\title{
Expression of vascular endothelial growth factor and glial fibrillary acidic protein in a rat model of traumatic brain injury treated with honokiol: a biochemical and immunohistochemical study
}

\author{
A. Çetin 1 , E. Deveci \\ 'Department of Neurosurgery, University of Health Sciences, Gazi Yaşargil Education and Research Hospital, Diyarbakır, Turkey \\ 2Department of Histology and Embryology, Faculty of Medicine, Dicle University, Diyarbakır, Turkey
}

[Received: 6 December 2018; Accepted: 7 February 2019]

Background: Traumatic brain injury (TBI) leads to neuronal damage and neurological dysfunction. The aim of our study was to investigate the antioxidative effect of honokiol on TBI in rats with biochemical, histopathological and immunohistochemical methods.

Materials and methods: Sprague-Dawley rats were subjected to TBI with a weight-drop device using $300 \mathrm{~g} / 1 \mathrm{~m}$ weight/height impact. Forty-five rats were divided into three groups as control group, TBI group and TBI + honokiol group ( $5 \mathrm{mg} / \mathrm{kg} /$ day, i.p.). Honokiol (5 $\mathrm{mg} / \mathrm{kg}$ ) dissolved in dimethyl sulfoxide (DMSO) was intraperitoneally administered to rats for 7 days after the trauma. At the end of experiment, blood samples were taken from the animals and analysed with various biochemical markers.

Results: Histopathological examination of the trauma group revealed some degenerated pyramidal cells, dilatation and congestion in blood vessels, hyperplasia in endothelial cells, inflammatory cell infiltration around the vein and disruptions in glial extensions. In TBI + honokiol group, pyramidal neurons showed a decrease in degeneration, slight dilatation in blood vessels, improvement of endothelial cells towards the lumen, and reduction of inflammatory cells in the vessel. In TBI + honokiol group, vascular endothelial growth factor expression was positive in the endothelial and few inflammatory cells of the mildly dilated blood vessels. In the blood brain barrier deteriorated after trauma, it was observed that the glial foot processes were positive expression and extended to the endothelial cells in the $T B I+$ honokiol group.

Conclusions: Glial fibrillary acidic protein expression showed a positive reaction in these processes. Considering the important role of antioxidants and inflammatory responses in cerebral damage induced by traumatic head injury, honokiol is thought to be important in decreasing lipid peroxidation, protecting the membrane structure of blood brain barrier, degeneration of neurons and glial cells. (Folia Morphol 2019; 78, 4: 684-694)

Key words: traumatic brain injury, honokiol, vascular endothelial growth factor, glial fibrillary acidic protein, rat

Address for correspondence: Prof. E. Deveci, PhD, Dicle University, Faculty of Medicine, Department of Histology and Embryology, 21280, Diyarbakır, Turkey, tel: +90 4122488001 ext. 4443 (faculty room), fax: +90 412 2488440, e-mail: devecie32@hotmail.com 


\section{INTRODUCTION}

Traumatic brain injury (TBI) is a health problem known as the cause of mortality and disability in young people. Primary and secondary injury cascades that cause delayed neuronal dysfunction, synapse loss and cell death are associated with TBI [1, 39]. Secondary damage develops within the minutes to days following the primary insult, release of the inflammatory mediators, formation of the free radicals, excessive release of the neurotransmitters (glutamate and aspartate), influx of calcium and sodium ions into neurons, and dysfunction of mitochondria [22]. At a cellular level, the biphasic nature of secondary injury is mediated by numerous disturbed pathways which include: excitotoxicity caused by an excess of the neurotransmitter glutamate; free radical generation by dysfunctional mitochondria, causing damage to proteins and phospholipid membranes of neurons and glia; the neuroinflammatory response which takes place due to both brain parenchyma and systemic immunoactivation [22, 31]. Glutamate is an excitatory amino acid which is known to play a role in the pathological events, increasing brainblood barrier permeability and the occurrence of oxidant damage. Previous studies have shown that glutamate antagonists may be beneficial in several conditions, such as ischaemia, sepsis and trauma $[1,22]$. The neuroinflammation is closely related to the overproduction of the reactive oxygen species which cause many neuropathologies. Free radicals damage various cellular components, including proteins, lipids and deoxyribonucleic acid. Antioxidants and anti-inflammatory drugs were widely studied in neurotrauma models [31]. After trauma, depending on the degree of brain damage, neuroinflammation, cerebral oedema and blood-brain barrier fragmentation occur. Vascular endothelial growth factor (VEGF) is a trophic factor that is expressed in the central nervous system after injury [10] and induces angiogenesis [34]. Inhibition of VEGF expression after trauma may exacerbate neuronal and glial injury [23]. However, increased endogenous VEGF interacts with ischaemic vessels with its receptors and contributes to the deterioration of the blood-brain barrier and subsequent leakage [51].

Glial fibrillary acidic protein (GFAP) is an intermediate filament protein found in the skeleton of astroglia. Data from studies have shown that increased local tissue GFAP immunoreactivity is a sensitive indicator of neuronal damage and its increase is considered to be a determinant of reactive astrocytosis. GFAP level in blood fluid increases when cerebral tissue or spinal cord cells are damaged due to trauma or disease $[15,41,50]$. This marker is in fact an indicator of the reaction of astrocytes in the form reactive gliosis.

Honokiol is a natural biphenolic compound that is isolated from magnolia bark and has been used in the traditional Chinese and Japanese medicine as an antibacterial, antiemetic, antidepressant, antithrombotic, and anxiolytic agent. Studies have shown therapeutic effects including antioxidative and anti-inflammatory activities for honokiol $[16,27,28]$.

Traumatic brain injury animal models are important in developing diagnostic and therapeutic strategies for understanding the pathophysiology of brain shocks [40]. In this study, antioxidative effects of honokiol on neuronal structures and changes in blood-brain barrier were investigated in TBI. In this study, we aimed to investigate antioxidative effects of honokiol on neuronal structures in a TBI model in rats with biochemical, histopathological and immunohistochemical methods.

\section{MATERIALS AND METHODS}

\section{Animals}

Every single surgical methodology and the consequent care and healing of the animals utilised as a part of this investigation were in strict understanding with the National Institutes of Health (NIH Publications No. 8023, revised 1978) rules for animal care. All techniques performed in this examination were approved by the Ethics Committee for Animal Experimentation of the Faculty of Medicine at Dicle University, Turkey. Male Sprague-Dawley rats (250-280 g) were housed in an air-conditioned room with 12-h light and dark cycles, where the temperature $\left(23 \pm 2^{\circ} \mathrm{C}\right)$ and relative humidity (65-70\%) were kept constant. All rats at the end of experiment were healthy and no difference in food/water consumption and body weight gain between experimental and control rats were observed.

\section{Traumatic brain injury model}

Sedation procedure. The animals were anesthetised by an intraperitoneal injection of $5 \mathrm{mg} / \mathrm{kg}$ xylazine $\mathrm{HCl}$ (Rompun, Bayer Health Care AG, Germany) and $40 \mathrm{mg} / \mathrm{kg}$ ketamine $\mathrm{HCl}$ (Ketalar, Pfizer Inc., USA), and were allowed to breathe spontaneously. A rectal probe was inserted, and the animals were 
positioned on a heating pad that maintained the body temperature at $37^{\circ} \mathrm{C}$.

Three groups (15 rats per group) were arranged as below:

- Control group: Isotonic saline solution (an equal volume of honokiol) was administered i.p. for 7 days;

- TBI group: The widely used diffuse brain injury model described by Marmarou et al. [31] was used. Briefly, a trauma device which works by dropping a constant weight from a specific height through a tube was used. A weight of $300 \mathrm{~g}$ was dropped from a $1 \mathrm{~m}$ height, which can induce mild trauma, as shown by Ucar et al. [46];

- TBI + honokiol group: Honokiol (5 mg/kg; Sigma-Aldrich Inc., St. Louis, MO, USA) dissolved in dimethyl sulfoxide (DMSO) was intraperitoneally administered for 7 days after the trauma. After 7 days, all animals were sacrificed by an intraperitoneal injection of $5 \mathrm{mg} / \mathrm{kg}$ xylazine $\mathrm{HCl}$ (Rompun, Bayer HealthCare AG, Germany) and $40 \mathrm{mg} / \mathrm{kg}$ ketamine $\mathrm{HCl}$ (Ketalar, Pfizer Inc., USA). After TBI, blood samples were taken from the animals and analysed with various biochemical markers. Then, parietal lobe of the brain cortex were rapidly removed. For the histological examination, brain tissues were fixed in $10 \%$ formaldehyde solution, post-fixed in $70 \%$ alcohol, and embedded in paraffin wax. The sections were stained with haematoxylin-eosin (H\&E).

\section{Malondialdehyde and glutathione peroxidase assays}

Tissue samples were homogenised with ice-cold $150 \mathrm{mM} \mathrm{KCl}$ for the determination of malondialdehyde (MDA) and glutathione peroxidase (GSH-Px) levels. The MDA levels were assayed for products of lipid peroxidation, and the results are expressed as $\mathrm{nmol} \mathrm{MDA} / \mathrm{g}$ tissue [42]. Glutathione was determined by the spectrophotometric method, which was based on the use of Ellman's reagent, and the results are expressed as $\mu \mathrm{mol}$ glutathione/g tissue [38].

\section{Myeloperoxidase assay}

Myeloperoxidase (MPO) activity in tissues was measured by a procedure similar to that described by Hillegas et al. [17]. Myeloperoxidase activity is expressed as $\mathrm{U} / \mathrm{g}$ tissue.

\section{Evans blue assay for blood-brain barrier permeability}

To evaluate the blood-brain barrier integrity, Evans blue (EB) dye was used as a marker of albumin extravasation [14]. EB was expressed as $\mu \mathrm{g} / \mathrm{mg}$ of brain tissue against a standard curve.

\section{Immunohistochemical technique}

Formaldehyde-fixed tissue was embedded in paraffin wax for further immunohistochemical examination. Sections were deparaffinised in xylene. Antigen retrieval process was performed twice in citrate buffer solution (pH: 6.0), first for $7 \mathrm{~min}$, and second for $5 \mathrm{~min}$, boiled in a microwave oven at $700 \mathrm{~W}$. They were allowed to cool to room temperature for $30 \mathrm{~min}$ and washed twice in distilled water for $5 \mathrm{~min}$. Endogenous peroxidase activity was blocked in $0.1 \%$ hydrogen peroxide for $20 \mathrm{~min}$. UItra V block (Cat. No:85-9043, Invitrogen, Carlsbad, CA, USA) was applied for $10 \mathrm{~min}$ prior to the overnight application of primary antibodies VEGF antibody (Cat. No: RB-222-P0) (1:100 dilution), GFAP antibody (1:100 dilution) (Cat. No: PA3-067, Invitrogen, Carlsbad, CA, USA). Secondary antibody (Cat. No: 85- 9043, Invitrogen, Carlsbad, CA, USA) was applied for $20 \mathrm{~min}$. Slides were then exposed to streptavidin-peroxidase for $20 \mathrm{~min}$. Chromogen diaminobenzidine (DAB) (Invitrogen, Cat. No: 34002 Carlsbad, CA, USA) was used. Control slides were prepared as mentioned above, but omitting the primary antibodies. After counterstaining with haematoxylin, and washing in tap water for $8 \mathrm{~min}$ and in distilled water for $10 \mathrm{~min}$, the slides were mounted with Entellan.

\section{Statistical analysis}

Statistical analysis of biochemical findings was carried out using GraphPad Prism 4.0 software (GraphPad Software, 2003, San Diego, CA, USA). All data are presented as mean \pm standard deviation (SD). Groups of data were compared with an analysis of variance (ANOVA) followed by Tukey's multiple comparison tests. Values of $p<0.001$ and $p<0.01$ were considered as statistically significant (Fig. 1). For the statistical analysis of VEGF and GFAP expression, Kruskal-Wallis and Mann-Whitney $U$ non-parametric statistical tests were used in the intergroup comparisons depending on the variables and the results were given as the mean \pm SD and mean rank. And, the results were considered statistically significant for $p=0$ with Kruskal-Wallis test and $p<0.05$ with Mann-Whitney $U$ test (Table 1). 

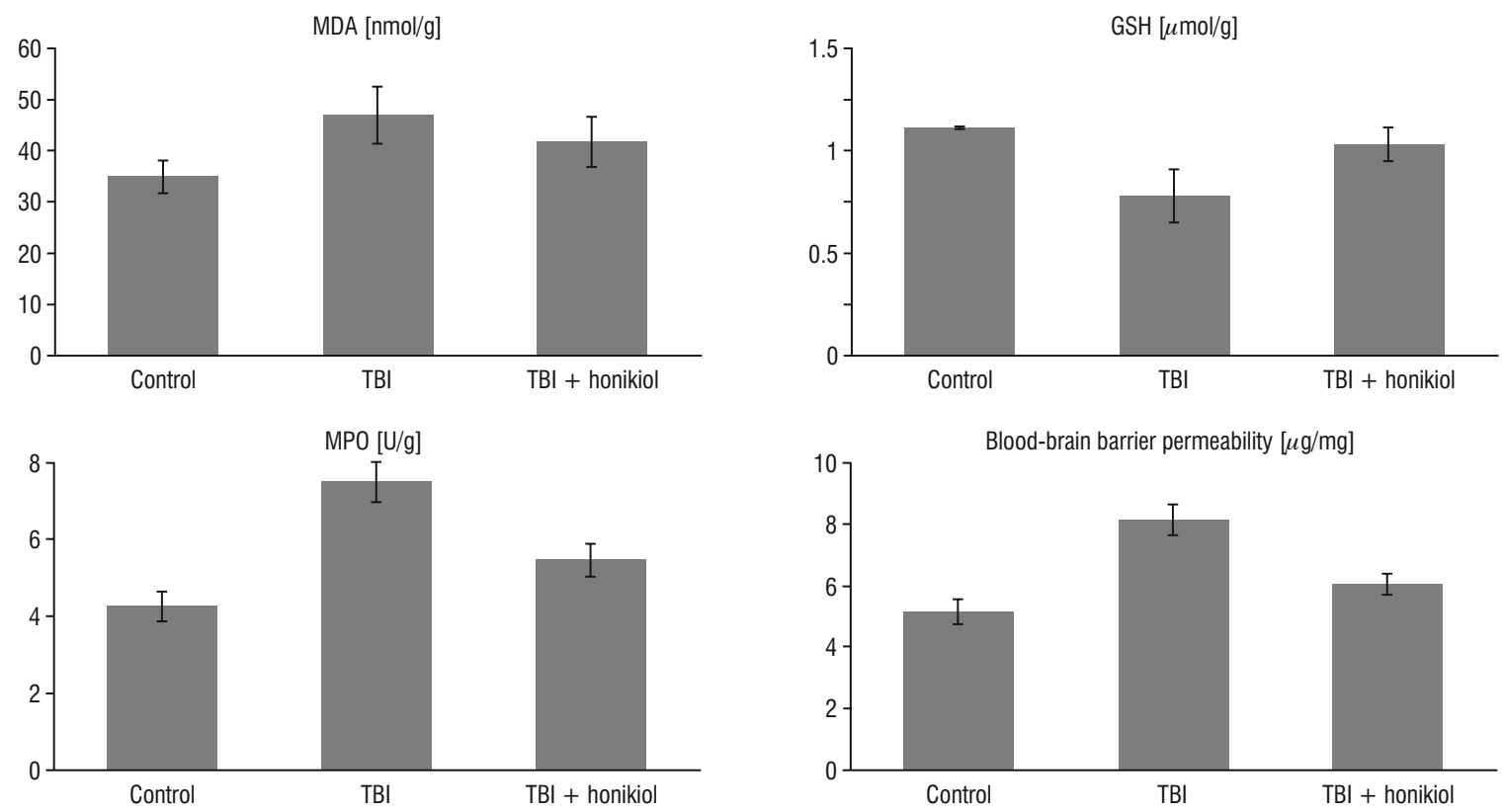

Figure 1. Biochemical results relevant to the study groups; abbreviations — see text.

Table 1. Histopathological scoring of vascular endothelial growth factor (VEGF) and glial fibrillary acidic protein (GFAP) expressions

\begin{tabular}{llccccc}
\hline & \multicolumn{5}{c}{ Histopathological scoring of control and experimental groups } \\
\hline Parameter & Groups & N & Mean \pm SD & Mean rank & $\begin{array}{c}\text { Kruskal-Wallis } \\
\text { test value }\end{array}$ & $\begin{array}{c}\text { Mann-Whitney U comparisons } \\
\text { for groups (p < 0.05) }\end{array}$ \\
\hline VEGF expression & (1) Control & 15 & $1.81 \pm 0.65$ & 17.08 & & $(2)^{* *}$ \\
& (2) TBI & 15 & $3.12 \pm 0.71$ & 30.12 & $19.397 ; ;^{*} p=0$ & $(1)^{* *}(3)^{* *}$ \\
& (3) TBI + honokiol & 15 & $2.00 \pm 0.73$ & 44.30 & & $(2)^{* *}$ \\
GFAP expression & (1) Control & 15 & $3.31 \pm 0.60$ & 10.50 & & $(2)^{* *}$ \\
& (2) TBI & 15 & $1.37 \pm 0.61$ & 33.65 & $34.034 ; * p=0$ & $(1)^{* *}(3)^{* *}$ \\
& (3) TBI + honokiol & 15 & $3.06 \pm 044$ & 47.35 & & $(2)^{* *}$ \\
\hline
\end{tabular}

Data are expressed as the mean \pm standard deviation (SD) and mean rank $\left({ }^{*} p=0\right.$ with Kruskal-Wallis test, ${ }^{* *} p<0.05$ with Mann-Whitney $U$ test, ${ }^{*}$ and ${ }^{* *}-$ statistically significant result). The quantification of all parameters: $0-$ no change, 1 - too week, 2 - week, $3-$ middle, $4-$ strong (Scoring was determined by examining histological parameters in 15 different regions within the microscope field); TBI — traumatic brain injury

\section{RESULTS}

\section{Biochemical findings}

The following biochemical parameters were compared between groups (Fig. 1).

\section{Tissue MDA levels}

Malondialdehyde values in the trauma (TBI) group were significantly higher than those of the control group ( $p<0.001$ ), while the TBI + honokiol group had significantly lower levels than those of the trauma (TBI) group $(p<0.001)$.

\section{Tissue GSH-Px levels}

Glutathione peroxidase levels of the control group were significantly higher than those of the trauma group ( $p<0.01$ ), while those of the TBI + honokiol group were also significantly higher than those of the trauma group $(p<0.01)$.

\section{Tissue MPO activity}

Myeloperoxidase levels of the control group were significantly lower than those of the trauma group $(p<0.01)$, while those of the TBI + honokiol group were also significantly lower than those of the trauma group $(p<0.01)$.

\section{Evans blue assay for blood-brain barrier permeability}

Blood-brain barrier permeability values of the control group were significantly lower than those of 
the trauma group ( $p<0.001)$, while those of the TBI + honokiol group were also significantly lower than those of the trauma group $(p<0.001)$.

\section{Histopathologic findings}

When brain cortex of the control group was examined, the pyramidal neurons were polyhedral and had chromatin-rich nuclei. Glial cells were observed with small round nuclei and distributed solitary.

The lumen of the capillary vessels in the cortex was regular and the endothelial cells were flat (Fig. 2a). Histopathological examination of the TBI group revealed some degenerated pyramidal cells, pyknotic nuclei, dilated and congested blood vessels, hyperplasia in endothelial cells, inflammatory cell infiltration around the vein and disruptions in glial extensions (Fig. 2b). In the histopathological examination of the TBI + honokiol group, we observed a decrease in degenerated pyramidal neurons, polygonal and dense-chromatin nuclei, slight dilated blood vessels and flattened endothelial cells towards the lumen and decrease in inflammatory cells around the vessel (Fig. 2c).

\section{Immunohistochemical findings}

Vascular endothelial growth factor expression in the capillary endothelial and some glial cells in the cortex showed a positive reaction in the control group sections (Fig. 3a). In the TBI group, glial cells around some degenerated neurons, dilated capillary endothelial cells and vascular inflammatory cells showed increased VEGF expression (Fig. 3b). In the $\mathrm{TBI}+$ honokiol group, VEGF expression was positive in the endothelial and few inflammatory cells of the mildly dilated blood vessels (Fig. 3c). When GFAP expression was examined in the control group, it was observed that the glial foot processes around the capillary vein covered the basement membrane like a meshwork and were firmly bound to the endothelial cells, and the expression of GFAP protein was significant (Fig. $3 \mathrm{~d}$ ). In the TBI group, loss of glial extensions was observed with deterioration of the glial food processes around the dilated capillary vessels. GFAP positive expression was observed in the short thick extensions away from the vessels (Fig. 3e). A significant increase in GFAP expression was observed in the glial food processes that covered the lumen of regular capillaries in the TBI + honokiol group (Fig. 3f).

\section{DISCUSSION}

Shortly after TBI, lack of blood flow causes necrotic neuronal death; however, greater loss of apoptotic
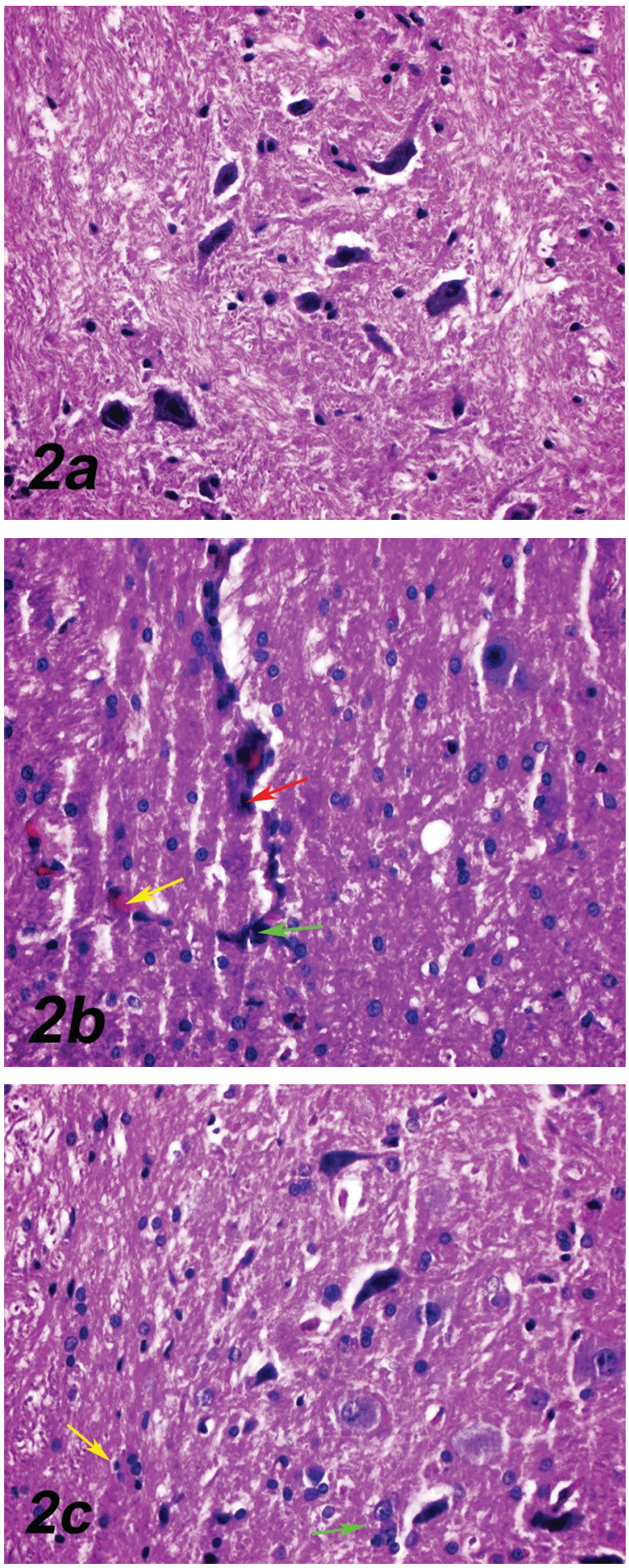

Figure 2. a. Haematoxylin and eosin (H\&E) staining, original magnification $\times 40$ (Control group). Normal appearance of regular cells and vascular structures in brain cortex; $\mathbf{b}$. H\&E staining, original magnification $\times 40$ (TBI group). Dilation in blood vessels and haemorrhage (yellow arrow), degenerative changes in some neurons, hyperplasia in endothelial cells (red arrow), inflammatory cell infiltration around blood vessels (green arrow) and disruptions in glial extensions; c. H\&E staining, original magnification $\times 40$ (TBI + honokiol group). Reduction in vascular dilatation (yellow arrow), flat endothelial cells towards the lumen, and decrease in inflammatory cells around the blood vessel (green arrow), regular structure of the nucleus and cytoplasm in neurons and glial cells; $\mathrm{TBI}$ - traumatic brain injury. 

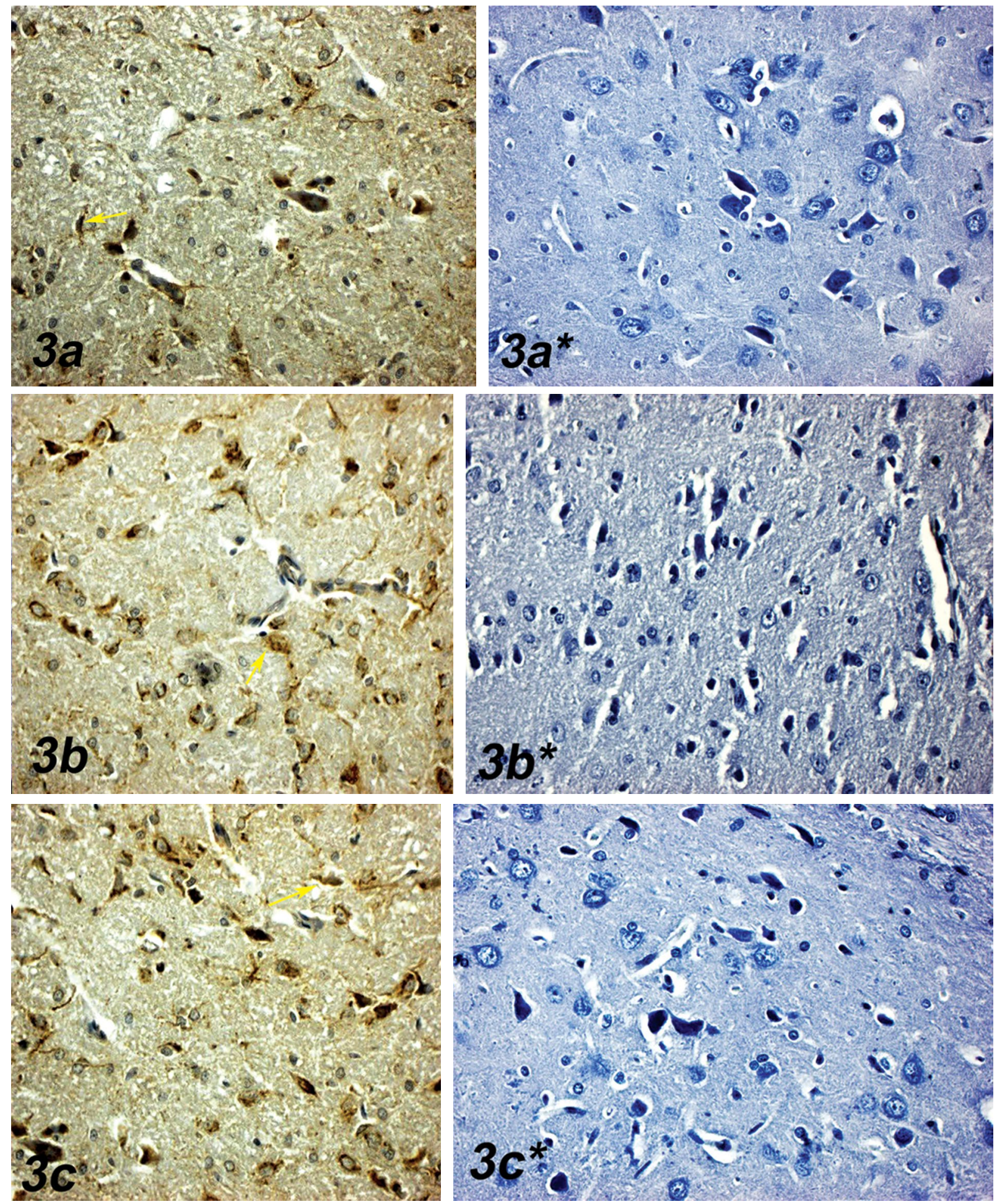

Figure 3. a. Vascular endothelial growth factor (VEGF) immunostaining, original magnification $\times 40$ (Control group). VEGF expression in the capillary endothelial (yellow arrow), and some glial cells in the cortex; $\mathbf{a}^{*}$. Negative control, haematoxylin staining, original magnification $\times 40$; b. VEGF immunostaining, original magnification $\times 40$ (TBI group). An increase in VEGF expression glial cells around some degenerated neurons and dilated capillary endothelial and vascular inflammatory cells (yellow arrow); $\mathbf{b}^{*}$. Negative control, haematoxylin staining, original magnification $\times 40$; c. VEGF immunostaining, original magnification $\times 40$ (TBI + honokiol group). Positive VEGF expression in the endothelial and few inflammatory cells of the mildly dilated blood vessels (yellow arrow); $\mathbf{c}^{*}$. Negative control, haematoxylin staining, original magnification $\times 40$; TBI — traumatic brain injury. 

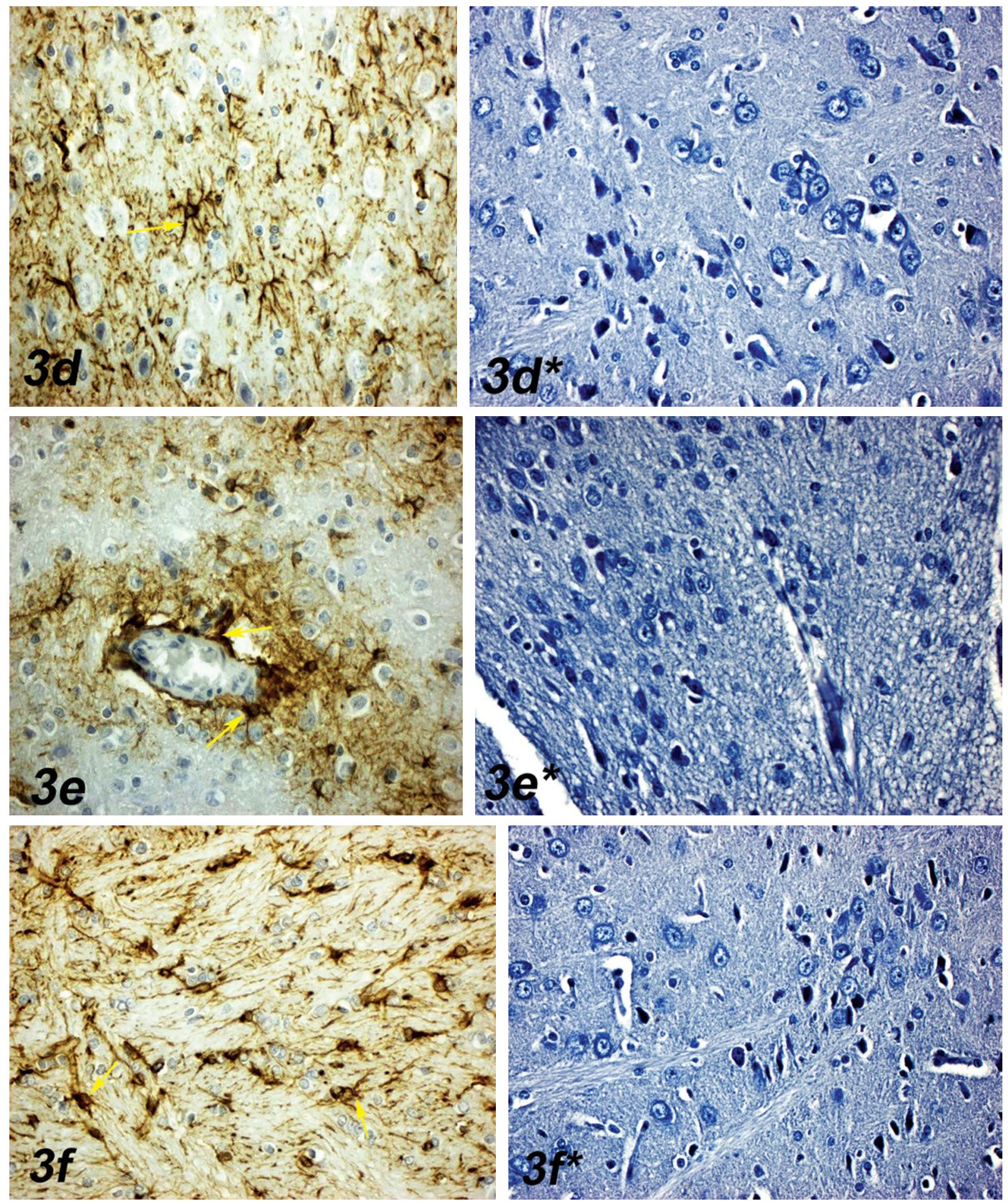

Figure 3. d. Glial fibrillary acidic protein (GFAP) immunostaining, original magnification $\times 40$ (Control group). Positive GFAP expression in glial food processes around the capillary vessel (yellow arrow); $\mathbf{d}^{*}$. Negative control, haematoxylin staining, original magnification $\times 40$; e. GFAP immunostaining, original magnification $\times 40$ (TBI group). Loss and degeneration in glial food processes around the dilated capillary vessels, positive GFAP expression (yellow arrows); $\mathbf{e}^{*}$. Negative control, haematoxylin staining, original magnification $\times 40 ; \mathbf{f}$. GFAP immunostaining, original magnification $\times 40$ (TBI + honokiol group). An increase GFAP expression in glial food processes (yellow arrows); $\mathbf{f}^{*}$. Negative control, haematoxylin staining, original magnification $\times 40$; TBI - traumatic brain injury. 
neurons may then occur after secondary injury of hypoxia/ischaemia and oxidative stress and inflammation $[8,9,12]$.

Previous studies have shown that a variety of pathological factors, such as oxidative stress, the inflammatory response and apoptosis, are involved in secondary brain injury after TBI. Furthermore, early interventions to reduce the level of oxidative stress and the extent of the inflammatory response can significantly reduce the extent of TBI [13]. Baloğlu et al. [2] observed a significant increase in MDA levels in spinal cord injury and a significant decrease in level of GSH and MPO. They have observed degenerative changes in some multipolar and bipolar nerve cells and pyknotic changes in the nucleus of glial cells.

Traumatic brain injury initiates a neuroinflammatory cascade characterised by microglial activation and increased production of proinflammatory cytokines [24]. TBI often promotes disruption of blood-brain barrier integrity and the neurovascular unit, which can result in vascular leakage, oedema, haemorrhage, and hypoxia. Other pathologic mechanisms include cell death within the meninges and brain parenchyma, stretching and tearing of axonal fibres, and disruptions at the junctions between white and grey matter, stemming from rotational forces that cause shearing injuries [3]. In this study, histopathological examination of the TBI group revealed some degenerated pyramidal cells, pyknotic nuclei, dilated and congested blood vessels, hyperplasia in endothelial cells, inflammatory cell infiltration around the vein and disruptions in glial extensions (Fig. 2b). In the TBI + honokiol group, pyramidal neurons were less degenerated, also there were slight dilatation of blood vessels, improvement of endothelial cells towards the lumen, and reduction of inflammatory cells in the vessel (Fig. 2c). Feng et al. [11] reported that TBI can result in synapse loss or damage and may contribute to observed behavioural, cognitive, and neurological disorders.

Vascular endothelial growth factor is effective on vascular and neural development. It was thought that brain oedema was dominant because of the increase in VEGF expression and blood-brain barrier destruction in the post-traumatic contusion stage $[6,43]$. Lenzlinger et al. [23] found that inhibition of VEGF significantly reduced regional cerebral oedema in TBI rats. Krum and Khaibullina [19] showed that inhibition of VEGF signals, including VEGF-R1 receptors, decreased the numbers of reactive astrocytes and prevented glial scar formation in TBI models. In our TBI group, an increase in VEGF expression levels, vascular permeability, and rapid interaction of VEGF receptors in endothelial cells led to the destruction of vascular wall in the blood-brain barrier and the formation of oedema. The neuroprotective function of VEGF is thought to be due to a combination of direct neuroprotective effects and stimulation of angiogenesis. GFAP, a brain-specific protein that acts as the major integral component of the cell skeleton of astrocytes, GFAP after brain injury discharges the brain cells into the interstitial fluid in the environment and causes deterioration in the blood-brain barrier [32]. An increase in GFAP expression is a cardinal feature of many pathological conditions of the central nervous system and astrocytes. Increasing numbers of GFAP positive expression astroglia cells following TBI have been described in several experimental studies in animals. GFAP was positively expressed in the normal brain tissue, processes in astrocytes around bloodbrain barrier rupture was defined as significant GFAP expression [15, 50]. Özevren et al. [37] showed that glial food processes around the blood vessels were decreased and GFAP expression was positive after trauma.

Honokiol with its antioxidant effects was shown to provide protection against cerebral ischaemia-reperfusion (I/R) injuries and dermatological disorders [52]. It has been reported that honokiol can provide potential support to clinical trials in ischaemia treatment by passing through the blood-brain barrier in low-dose long-term treatments [48]. Honokiol has been reported to protect the rat brain from focal cerebral ischaemia-reperfusion (I/R) injury by inhibiting neutrophil infiltration and production of reactive oxygen species [28]. In a similar way to our study, they investigated the effects of honokiol, a cell cycle inhibitor, on neuronal damage reduction and functional recovery after TBI in rats. They demonstrated that honokiol, administered intravenously, has a strong neuroprotective effect against sensorimotor and cognitive deficits after TBI, which is highly associated with the survival of increased neurons. It has been suggested that the neurocompatibility mediated by honokiol after TBI may affect the molecular mechanism due to suppression of over-activated cell cycle [47]. Talerek et al. [45] have made a comprehensive assessment of the potential molecular mechanisms of action that are considered as a promising agent in the treatment and management of neurodegenerative 
diseases concerning the neuroprotective effects of honokiol [45]. In the experimental studies, it was stated that honokiol plays an active agent role in the central nervous system. Antioxidant activity, inhibition of excitotoxicity; and cell signalling in neuroinflammation has been shown as evidences on its neuroprotective activity $[20,21,25,26,48,49]$. In studies of experimental and human cell culture, it has been reported that honokiol can reduce oxidative stress parameters in several catabolic tissues such as liver [44], endothelial cells [36], muscle tissue [5], heart or kidney [30]. However, there is little information in studies demonstrating the oxidative inhibition of honokoil in the central nervous system. Chuang et al. [7] studied the effect of honokiol on oxidative stress and inflammation in neural and microglial cells. They investigated the oxidative and inflammatory responses of these isomers in microglial cells activated by interferon-gamma and lipopolysaccharide in suppressing oxidative stress in neuronal stimulated neurons by ionotropic glutamate receptor agonist $\mathrm{N}$-methyl-D-aspartate. And, they also investigated the mechanism and signalling pathways involved in cytokine-induced production of reactive oxygen species in microglial cells. Their results of microglial cells also demonstrated the important role of interferon-gamma in stimulating signalling pathways involving activation of extracellular signal-regulated protein kinases 1 and 2 , reactive oxygen species and nitric oxide. Studies have shown that honokiol inhibits reactive oxygen species in neutrophils [28] and suppresses the lipopolysaccharide-induced tumour necrosis factor alpha and nitric oxide expression in macrophages [18]. In addition, some authors suggest that honokiol can inhibit nuclear factor kappa light chain enhancer of activated $B$ cells activation in mouse B cells [31], macrophages [4] and lipopolysaccharide-induced microglia cells [52]. It is also believed that honokiol can selectively modulate the phosphoinositide 3-kinase/Akt pathway [18, 35, 53].

\section{CONCLUSIONS}

The neuroprotective effect of honokiol was found to be parallel to the reduction of lipid peroxidation and inhibition of inflammatory cell in cerebral tissue. After trauma, the structure of glial food processes deteriorates along with the increase in inflammation towards endothelial cells. Due to the effect of honokiol, the improvement of vascular wall due to decreased inflammation in this region and the regular distribution of glial food processes define the antioxidative development. Considering the important role of antioxidants and inflammatory responses in cerebral damage induced by traumatic head injury, honokiol is thought to be important in decreasing lipid peroxidation and protecting the membrane structure of blood-brain barrier, degeneration of neurons and glial cells.

\section{REFERENCES}

1. Baldwin SA, Gibson T, Callihan CT, et al. Neuronal cell loss in the CA3 subfield of the hippocampus following cortical contusion utilizing the optical disector method for cell counting. J Neurotrauma. 1997; 14(6): 385-398, doi: 10.1089/neu.1997.14.385, indexed in Pubmed: 9219853.

2. Baloğlu M, Çetin A, Tuncer MC. Neuroprotective effects of Potentilla fulgens on spinal cord injury in rats: an immunohistochemical analysis. Folia Morphol. 2018 [Epub ahead of print], doi: 10.5603/FM.a2018.0050, indexed in Pubmed: 30402877.

3. Blennow $\mathrm{K}$, Hardy J, Zetterberg $\mathrm{H}$. The neuropathology and neurobiology of traumatic brain injury. Neuron. 2012; 76(5): 886-899, doi: 10.1016/j.neuron.2012.11.021, indexed in Pubmed: 23217738.

4. Chao LK, Liao PC, Ho CL, et al. Anti-inflammatory bioactivities of honokiol through inhibition of protein kinase $C$, mitogen-activated protein kinase, and the NF-kappaB pathway to reduce LPS-induced TNFalpha and NO expression. J Agric Food Chem. 2010; 58(6): 3472-3478, doi: 10.1021/jf904207m, indexed in Pubmed: 20192217.

5. Chiang J, Shen YC, Wang YH, et al. Honokiol protects rats against eccentric exercise-induced skeletal muscle damage by inhibiting NF-kappaB induced oxidative stress and inflammation. Eur J Pharmacol. 2009; 610(1-3): 119-127, doi: 10.1016/j.ejphar.2009.03.035, indexed in Pubmed: 19303869.

6. Chodobski A, Chung I, Koźniewska E, et al. Early neutrophilic expression of vascular endothelial growth factor after traumatic brain injury. Neuroscience. 2003; 122(4): 853-867, doi: 10.1016/j.neuroscience.2003.08.055, indexed in Pubmed: 14643756.

7. Chuang DY, Chan MH, Zong Y, et al. Magnolia polyphenols attenuate oxidative and inflammatory responses in neurons and microglial cells. J Neuroinflammation. 2013; 10: 15, doi: 10.1186/1742-2094-10-15, indexed in Pubmed: 23356518.

8. Coles JP. Regional ischemia after head injury. Curr Opin Crit Care. 2004; 10(2): 120-125.

9. Diaz-Arrastia R, Kochanek PM, Bergold P, et al. Pharmacotherapy of traumatic brain injury: state of the science and the road forward: report of the Department of Defense Neurotrauma Pharmacology Workgroup. J Neurotrauma. 2014; 31(2): 135-158, doi: 10.1089/neu.2013.3019, indexed in Pubmed: 23968241.

10. Dore-Duffy $P$, Wang $X$, Mehedi A, et al. Differential expression of capillary VEGF isoforms following traumatic brain injury. Neurol Res. 2007; 29(4): 395-403, doi: 10.1179/016164107X204729, indexed in Pubmed: 17626736 . 
11. Feng $Y$, Cui $Y$, Gao JL, et al. Neuroprotective effects of resveratrol against traumatic brain injury in rats: Involvement of synaptic proteins and neuronal autophagy. Mol Med Rep. 2016; 13(6): 5248-5254, doi: 10.3892/ mmr.2016.5201, indexed in Pubmed: 27122047.

12. Greve MW, Zink BJ. Pathophysiology of traumatic brain injury. Mt Sinai J Med. 2009; 76(2): 97-104, doi: 10.1002/ msj.20104, indexed in Pubmed: 19306379.

13. Gyoneva S, Ransohoff RM. Inflammatory reaction after traumatic brain injury: therapeutic potential of targeting cell-cell communication by chemokines. Trends Pharmacol Sci. 2015; 36(7): 471-480, doi: 10.1016/j. tips.2015.04.003, indexed in Pubmed: 25979813.

14. Hakan T, Toklu HZ, Biber N, et al. Effect of COX-2 inhibitor meloxicam against traumatic brain injury-induced biochemical, histopathological changes and blood-brain barrier permeability. Neurol Res. 2010; 32(6): 629-635, doi: 10.1179/016164109X12464612122731, indexed in Pubmed: 19660237.

15. Hausmann $R$, Riess $R$, Fieguth $A$, et al. Immunohistochemical investigations on the course of astroglial GFAP expression following human brain injury. Int J Legal Med. 2000; 113(2): 70-75, indexed in Pubmed: 10741479.

16. Hayashi T, Saito A, Okuno $S$, et al. Damage to the endoplasmic reticulum and activation of apoptotic machinery by oxidative stress in ischemic neurons. J Cereb Blood Flow Metab. 2005; 25(1): 41-53, doi: 10.1038/sj.jcbfm.9600005, indexed in Pubmed: 15678111.

17. Hillegass LM, Griswold DE, Brickson B, et al. Assessment of myeloperoxidase activity in whole rat kidney. J Pharmacol Methods. 1990; 24(4): 285-295, indexed in Pubmed: 1963456.

18. Kim BH, Cho JY. Anti-inflammatory effect of honokiol is mediated by PI3K/Akt pathway suppression. Acta Pharmacol Sin. 2008; 29(1): 113-122, doi: 10.1111/j.17457254.2008.00725.x, indexed in Pubmed: 18158873.

19. Krum JM, Khaibullina A. Inhibition of endogenous VEGF impedes revascularization and astroglial proliferation: roles for VEGF in brain repair. Exp Neurol. 2003; 181(2): 241-257, doi: 10.1016/s0014-4886(03)00039-6, indexed in Pubmed: 12781997.

20. Kuribara $H$, Kishi $E$, Kimura $M$, et al. Comparative assessment of the anxiolytic-like activities of honokiol and derivatives. Pharmacol Biochem Behav. 2000; 67(3): 597-601, doi: 10.1016/s0091-3057(00)00401-9, indexed in Pubmed: 11164091.

21. Kuribara H, Stavinoha WB, Maruyama Y. Honokiol, a putative anxiolytic agent extracted from magnolia bark, has no diazepam-like side-effects in mice. J Pharm Pharmacol. 1999; 51(1): 97-103, indexed in Pubmed: 10197425.

22. Lee S, Park S, Won J, et al. The Incremental Induction of Neuroprotective Properties by Multiple Therapeutic Strategies for Primary and Secondary Neural Injury. Int J Mol Sci. 2015; 16(8): 19657-19670, doi: 10.3390/ijms160819657, indexed in Pubmed: 26295390.

23. Lenzlinger PM, Saatman KE, Hoover RC, et al. Inhibition of vascular endothelial growth factor receptor (VEGFR) signaling by BSF476921 attenuates regional cerebral edema following traumatic brain injury in rats. Restor Neurol Neurosci. 2004; 22(2): 73-79, indexed in Pubmed: 15272142.

24. Lim SW, Wang CC, Wang YH, et al. Microglial activation induced by traumatic brain injury is suppressed by postin- jury treatment with hyperbaric oxygen therapy. J Surg Res. 2013; 184(2): 1076-1084, doi: 10.1016/j.jss.2013.04.070, indexed in Pubmed: 23726237.

25. Lin JW, Chen JT, Hong CY, et al. Honokiol traverses the blood-brain barrier and induces apoptosis of neuroblastoma cells via an intrinsic bax-mitochondrion-cytochrome c-caspase protease pathway. Neuro Oncol. 2012; 14(3): 302-314, doi: 10.1093/neuonc/nor217, indexed in Pubmed: 22259050 .

26. Lin YR, Chen HH, Lin YC, et al. Antinociceptive actions of honokiol and magnolol on glutamatergic and inflammatory pain. J Biomed Sci. 2009; 16: 94, doi: 10.1186/14230127-16-94.

27. Liou KT, Lin SM, Huang SS, et al. Honokiol ameliorates cerebral infarction from ischemia-reperfusion injury in rats. Planta Med. 2003; 69(2): 130-134, doi: 10.1055/s2003-37707, indexed in Pubmed: 12624817.

28. Liou KT, Shen YC, Chen CF, et al. Honokiol protects rat brain from focal cerebral ischemia-reperfusion injury by inhibiting neutrophil infiltration and reactive oxygen species production. Brain Res. 2003; 992(2): 159-166, doi: 10.1016/j.brainres.2003.08.026, indexed in Pubmed: 14625055

29. Liou KT, Shen YC, Chen CF, et al. The anti-inflammatory effect of honokiol on neutrophils: mechanisms in the inhibition of reactive oxygen species production. Eur J Pharmacol. 2003; 475(1-3): 19-27, doi: 10.1016/s00142999(03)02121-6, indexed in Pubmed: 12954355.

30. Lo YC, Teng CM, Chen CF, et al. Magnolol and honokiol isolated from Magnolia officinalis protect rat heart mitochondria against lipid peroxidation. Biochem Pharmacol. 1994; 47(3): 549-553, doi: 10.1016/0006-2952(94)901872, indexed in Pubmed: 8117323.

31. Marmarou A, Foda MA, van den Brink W, et al. A new model of diffuse brain injury in rats. Part I: Pathophysiology and biomechanics. J Neurosurg. 1994; 80(2): 291-300, doi: 10.3171/jns.1994.80.2.0291, indexed in Pubmed: 8283269.

32. Missler U, Wiesmann M, Wittmann G, et al. Measurement of glial fibrillary acidic protein in human blood: analytical method and preliminary clinical results. Clin Chem. 1999; 45(1): 138-141, indexed in Pubmed: 9895354.

33. Munroe ME, Arbiser JL, Bishop GA. Honokiol, a natural plant product, inhibits inflammatory signals and alleviates inflammatory arthritis. J Immunol. 2007; 179(2): 753-763, doi: 10.4049/jimmunol.179.2.753, indexed in Pubmed: 17617564.

34. Nag S, Takahashi JL, Kilty DW. Role of vascular endothelial growth factor in blood-brain barrier breakdown and angiogenesis in brain trauma. J Neuropathol Exp Neurol. 1997; 56(8): 912-921, doi: 10.1097/00005072-19970800000009, indexed in Pubmed: 9258261.

35. Nakano N, Matsuda S, Ichimura M, et al. PI3K/AKT signaling mediated by $\mathrm{G}$ protein-coupled receptors is involved in neurodegenerative Parkinson's disease (Review). Int J Mol Med. 2017; 39(2): 253-260, doi: 10.3892/ ijmm.2016.2833, indexed in Pubmed: 28000847.

36. Ou HC, Chou FP, Lin TM, et al. Protective effects of honokiol against oxidized LDL-induced cytotoxicity and adhesion molecule expression in endothelial cells. Chem Biol Interact. 2006; 161(1): 1-13, doi: 10.1016/j.cbi.2006.02.006, indexed in Pubmed: 16580656. 
37. Özevren $H$, Irtegün $S$, Deveci $E$, et al. Neuroprotective effects of Potentilla fulgens on traumatic brain injury in rats. Anal Quant Cytol Histol. 2017; 39: 35-44.

38. Preston GW, Phillips DH. Quantification of a peptide standard using the intrinsic fluorescence of tyrosine. Anal Bioanal Chem. 2016; 408(9): 2187-2193, doi: 10.1007/ s00216-016-9334-1, indexed in Pubmed: 26879647.

39. Scheff SW, Price DA, Hicks RR, et al. Synaptogenesis in the hippocampal CA1 field following traumatic brain injury. J Neurotrauma. 2005; 22(7): 719-732, doi: 10.1089/ neu.2005.22.719, indexed in Pubmed: 16004576.

40. Shultz SR, McDonald SJ, Vonder Haar C, et al. The potential for animal models to provide insight into mild traumatic brain injury: Translational challenges and strategies. Neurosci Biobehav Rev. 2017; 76(Pt B): 396-414, doi: 10.1016/j.neubiorev.2016.09.014, indexed in $\mathrm{Pu}-$ bmed: 27659125.

41. Sofroniew MV, Vinters HV. Astrocytes: biology and pathology. Acta Neuropathol. 2010; 119(1): 7-35, doi: 10.1007/ s00401-009-0619-8, indexed in Pubmed: 20012068.

42. Sohrab G, Angoorani P, Tohidi M, et al. Pomegranate (Punicagranatum) juice decreases lipid peroxidation, but has no effect on plasma advanced glycated end-products in adults with type 2 diabetes: a randomized double-blind clinical trial. Food Nutr Res. 2015; 59: 28551, doi: 10.3402/ fnr.v59.28551, indexed in Pubmed: 26355954.

43. Stroop R, Thomale UW, Päuser S, et al. Magnetic resonance imaging studies with cluster algorithm for characterization of brain edema after controlled cortical impact injury (CCII). Acta Neurochir Suppl. 1998; 71: 303-305, indexed in Pubmed: 9779214.

44. Sulakhiya K, Kumar P, Gurjar SS, et al. Beneficial effect of honokiol on lipopolysaccharide induced anxiety-like behavior and liver damage in mice. Pharmacol Biochem Behav. 2015; 132: 79-87, doi: 10.1016/j.pbb.2015.02.015, indexed in Pubmed: 25725264.

45. Talarek S, Listos J, Barreca D, et al. Neuroprotective effects of honokiol: from chemistry to medicine. Biofactors. 2017; 43(6): 760-769, doi: 10.1002/biof.1385, indexed in Pubmed: 28817221.
46. Ucar T, Tanriover G, Gurer I, et al. Modified experimental mild traumatic brain injury model. J Trauma. 2006; 60(3): 558-565, doi: 10.1097/01.ta.0000209172.75637.db, indexed in Pubmed: 16531854.

47. Wang H, Liao Z, Sun $X$, et al. Intravenous administration of Honokiol provides neuroprotection and improves functional recovery after traumatic brain injury through cell cycle inhibition. Neuropharmacology. 2014; 86: 9-21, doi: 10.1016/j. neuropharm.2014.06.018, indexed in Pubmed: 24973706.

48. Wang X, Duan X, Yang G, et al. Honokiol crosses BBB and $B C S F B$, and inhibits brain tumor growth in rat $9 \mathrm{~L}$ intracerebral gliosarcoma model and human U251 xenograft glioma model. PLoS One. 2011; 6(4): e18490, doi: 10.1371/ journal.pone.0018490, indexed in Pubmed: 21559510.

49. Xu Q, Yi LT, Pan Y, et al. Antidepressant-like effects of the mixture of honokiol and magnolol from the barks of Magnolia officinalis in stressed rodents. Prog Neuropsychopharmacol Biol Psychiatry. 2008; 32(3): 715-725, doi: 10.1016/j. pnpbp.2007.11.020, indexed in Pubmed: 18093712.

50. Yuan TM, Yu HM, Gu WZ, et al. Expression of glial fibrillary acidic protein in developing rat brain after intrauterine infection. Neuropathology. 2004; 24(2): 136-143, indexed in Pubmed: 15139591.

51. Zhang Le, Deng M, Zhou S. Tetramethylpyrazine inhibits hypoxia-induced pulmonary vascular leakage in rats via the ROS-HIF-VEGF pathway. Pharmacology. 2011; 87(5-6): 265-273, doi: 10.1159/000326082, indexed in Pubmed: 21494058.

52. Zhang $P$, Liu X, Zhu Y, et al. Honokiol inhibits the inflammatory reaction during cerebral ischemia reperfusion by suppressing NF- $\kappa$ B activation and cytokine production of glial cells. Neurosci Lett. 2013; 534: 123-127, doi: 10.1016/j. neulet.2012.11.052, indexed in Pubmed: 23262090.

53. Zhou PH, Hu W, Zhang XB, et al. Protective Effect of Adrenomedullin on Rat Leydig Cells from Lipopolysaccharide-Induced Inflammation and Apoptosis via the PI3K/ Akt Signaling Pathway ADM on Rat Leydig Cells from Inflammation and Apoptosis. Mediators Inflamm. 2016; 2016: 7201549, doi: 10.1155/2016/7201549, indexed in Pubmed: 27212810. 